\title{
Lethal outbreak of infection with Clostridium novyi type $A$ and other spore-forming organisms in Scottish injecting drug users
}

\author{
CHRISTOPHER C. MCGUIGAN, GILLIAN M. PENRICE, LAURENCE GRUER, SYED AHMED, \\ DAVID GOLDBERG*, MARJORIE BLACK†, JANE E. SALMON† and JOHN HOOD§ \\ Greater Glasgow NHS Board, Glasgow, * Scottish Centre for Infection and Environmental Health, Glasgow, \\ $\uparrow$ University of Glasgow, Glasgow, \$Public Health Laboratory Service, London and Cardiff and §Glasgow Royal \\ Infirmary, Glasgow, Scotland
}

\begin{abstract}
This report describes the investigation and management of an unprecedented outbreak of severe illness among injecting drug users (IDUs) in Scotland during April to August 2000. IDUs with severe soft tissue inflammation were prospectively sought among acute hospitals and a mortuary in Scotland. Cases were categorised as definite or probable: probable cases had severe injection site inflammation or multi-system failure; definite cases had both. Information about clinical course, mortality, post-mortem findings and laboratory data was gathered by standardised case-note review and interview. Sixty cases were identified - 23 definite and 37 probable. Most had familial or social links with each other and 50 were from Glasgow. Median age was 30 years; 31 were female. The majority, especially definite cases, injected heroin/citric acid extravascularly. Of definite cases, 20 died (87\% case-fatality rate; 13 after intensive care), 15 had necrotising fasciitis, 22 had injection site oedema and 13 had pleural effusion. Median white cell count was $60 \times 10^{9} / \mathrm{L}$. Of 37 probable cases, three died (8\% case-fatality rate). Overall, the most frequently isolated pathogen was Clostridium novyi type A (13 cases: 8 in definite cases). The findings are consistent with an infection resulting from injection into soft tissue of acidified heroin contaminated with spore-forming bacteria. Toxin production led to a severe local reaction and, in many, multi-system failure.
\end{abstract}

\section{Introduction}

Mortality rates in injecting drug user (IDU) populations are estimated to be 12-22 times higher than that for the age-adjusted population overall $[1,2]$. In Glasgow, Scotland, which had an estimated IDU population in 1990 of at least 8500 [3], 91 drug-related overdose deaths were recorded in 2000 [4]. IUDs are at high risk from various infections; for example, injection site abscesses are common among the city's IDUs, especially those who inject into soft tissue rather than veins [5]. In the UK, street heroin is usually sold as a base. It is typically heated with acid to dissolve it for injection [6].

On 4 May 2000, the microbiology department at Glasgow's Victoria Infirmary informed the public

Received 13 June 2002; accepted 4 July 2002.

Corresponding author: Dr C. McGuigan (e-mail: chris. mcguigan@fvhb.scot.nhs.uk). health department of the Greater Glasgow Health Board (GGHB) that two IDUs with similar clinical features had been admitted to the hospital's intensive therapy unit. Investigation of existing cases and a search for new ones commenced. By 8 May there were six known cases of which four had died. Cases were characterised by multi-organ failure associated with moderate to severe inflammation at or near an injecting site. At this point it was clear that there was an outbreak [7].

This report describes the outbreak and details the associated investigation, epidemiology, clinical features, gross pathology, microbiology and outbreak management. Aetiological hypotheses are presented.

\section{Patients and methods}

\section{Co-ordination of outbreak investigation}

GGHB's public health department co-ordinated the 
outbreak investigation. Representatives from public health, microbiology, forensic pathology, clinical infectious diseases, Strathclyde Police, the Procurator Fiscal's office and drug misuse services comprised the outbreak investigation team. An epidemiologist from the Centers for Disease Control and Prevention, Atlanta, USA (CDC), joined the Glasgow team to assist the investigation. A core team of public health specialists from GGHB and the Scottish Centre for Infection and Environmental Health (SCIEH) met daily during the height of the outbreak.

\section{Prospective case-finding}

Early in the investigation, the common clinical features of the cases were identified and case definitions were derived (Table 1). Prospective case-finding in Glasgow was initiated on 8 May 2000. This involved telephoning all accident and emergency departments, intensive therapy units and surgical high dependency units in Glasgow hospitals daily and communicating with the staff of Glasgow City Mortuary who handle all cadavers associated with drug-related deaths. SCIEH issued national and international alerts via the SCIEH Weekly Report and Eurosurveillance publications. Information was also disseminated via formal (e.g., ProMED Digest) and informal e-mail systems.

\section{Data collection and collation}

The outbreak investigation team interviewed all survivors whose characteristics met the definite and probable case definitions and studied their case-notes to obtain demographic, clinical and injecting practice information. For deceased cases, surrogates (close friends, spouses or family members) were interviewed. Demographic, clinical, pathological, microbiological and injecting practice data were entered into a secure database.

\section{Laboratory testing}

Heroin, blood and both ante- and post-mortem tissue and fluid samples were analysed by local hospital laboratories, the reference laboratories (in both London and Cardiff) of the Public Health Laboratory Service

Table 1. Outbreak case definitions

\begin{tabular}{|c|c|}
\hline \multicolumn{2}{|l|}{ Feature } \\
\hline 1. & $\begin{array}{l}\text { IDU presenting to hospital since } 1 \text { April } 2000 \text { with } \\
\text { significant inflammation at injecting site. }\end{array}$ \\
\hline 2. & $\begin{array}{l}\text { IDU with severe inflammatory process at or around } \\
\text { an injecting site. }\end{array}$ \\
\hline 3. & $\begin{array}{l}\text { Severe systemic reaction with evidence of multi-organ } \\
\text { failure. }\end{array}$ \\
\hline 4. & $\begin{array}{l}\text { Death outwith hospital: post-mortem findings } \\
\text { suggestive of septic or toxic shock. }\end{array}$ \\
\hline \multicolumn{2}{|l|}{ Case } \\
\hline \multicolumn{2}{|l|}{ status } \\
\hline \multicolumn{2}{|c|}{ Probable $=1+(2$ or 3$)$} \\
\hline \multicolumn{2}{|c|}{ Definite $=(1+2)+(3$ or 4$)$} \\
\hline
\end{tabular}

(PHLS) and laboratories at CDC. Tissue samples received by the PHLS were subjected to standard and enhanced anaerobic culture, with and without heat shock. The Centre for Applied Microbiology \& Research, Porton Down (CAMR) and CDC tested for Bacillus anthracis.

Clostridium species isolated on site from tissue or referred from local laboratories were identified phenotypically [8] at CDC and the PHLS laboratories; identification was confirmed, where necessary, by partial or full $16 \mathrm{~S}$ rDNA sequence analysis. The production of $\alpha$-toxin by $C$. novyi type A isolates was detected by a cytopathic effect [9] on Vero cell monolayers, which was neutralised by Gas Gangrene (Clostridium oedematiens) Antitoxin (3rd British Standard Established 1966) (64/24) National Institute for Biological Standards and Control, UK.

Nine heroin samples belonging to cases or their associates were cultured at local hospital laboratories, CAMR, PHLS and CDC.

\section{Retrospective case-finding}

The Department of Forensic Medicine, University of Glasgow performed a systematic search through records of all post-mortem examinations conducted in Glasgow during the previous 5 years to ascertain if any drug users had died in similar circumstances.

One of the characteristic features of the syndrome was a leukaemoid reaction - markedly raised white cell count (WCC) with left shift. This suggested a potentially sensitive method of identifying definite cases among previous inpatients. The haematology departments of two of the hospitals (A and B) that accounted for most of the Scottish cases were asked to identify any instances of WCC $>60 \times 10^{9} / \mathrm{L}$ that had been recorded during the year to June 2000. This threshold, being the median highest WCC of definite cases, would detect c. $50 \%$ of any previous cases. A lower cut-off was deemed impractical as it generated too many results for manual checking by the haematology departments. Furthermore, as screening by age was possible in hospital A, all instances of WCC $>30$ $\times 10^{9} / \mathrm{L}$ in the previous 6 months were sought for all patients aged under 50 years.

\section{Results \\ Epidemiology}

During April-August 2000, 60 cases (23 definite and 37 probable) were identified in Scotland; of these, 23 died (Table 2). All were IDUs who had injected a solution of street heroin and acid (usually citric) within 10 days of presentation. Of definite cases, $91 \%$ were tissue injectors or 'poppers' compared with $43 \%$ of probable cases $(\mathrm{P}<0.0006$, see Table 2$)$. Of the 19 
Table 2. Characteristics of definite and probable cases in Scotland

\begin{tabular}{|c|c|c|c|c|c|c|c|}
\hline \multirow[b]{2}{*}{ Case status } & \multirow[b]{2}{*}{ Total (dead) } & \multirow{2}{*}{$\begin{array}{c}\text { Age range } \\
\text { (median) (years) }\end{array}$} & \multirow{2}{*}{$\begin{array}{c}\text { Gender } \\
\text { (male/female) }\end{array}$} & \multicolumn{4}{|c|}{ Injection method } \\
\hline & & & & EV (\%) & IV only & Not known & Odds ratio $(95 \% \mathrm{CI})$ \\
\hline Definite & $23(20)$ & $20-48(30)$ & $12 / 11$ & $21(91.3)$ & 0 & 2 & $13.8(2.61-132)$ \\
\hline Probable & 37 (3) & $20-44(30)$ & $17 / 20$ & $16(43.2)$ & 18 & 3 & 1 \\
\hline Total & $60(23)$ & $20-48(30)$ & $29 / 31$ & $37(61.7)$ & 18 & 5 & $\ldots$ \\
\hline
\end{tabular}

$\mathrm{EV}$, extravascular; IV, intravenous.

definite cases from Glasgow, 17 resided in a narrow longitudinal transect of the city. At least 20 (54\%) of the 37 probable and $14(61 \%)$ of the 23 definite cases had social or familial links with each other.

\section{Clinical features}

A typical case presented with marked swelling and pain at an intramuscular injection site; however, in three of the definite cases (all of whom subsequently died) the initial presentation was of a simple abscess or cellulitis, or both. The clinical features are summarised in Table 3. Of particular note are the high WCCs with films characteristic of a leukaemoid reaction and the presence of oedema.

\section{Laboratory findings (Table 3)}

Microbiological and pathological data were available for the 55 cases who lived in Glasgow and the surrounding area; of these, 19 died and underwent a post-mortem examination. Frequent findings included necrotising fasciitis, profuse oedema and thoracic effusion; gas was found in only four.

In the West of Scotland, C. novyi type A was isolated from the specimens of 12 cases ( 7 ante-mortem and 5 post-mortem). However, no significant organism was isolated in 9 of 20 definite and 16 of 35 probable cases. A further $C$. novyi type A was isolated from one East of Scotland case. C. novyi rDNA was first detected by CDC from one fixed post-mortem specimen by $16 \mathrm{~S}$ rDNA PCR. All C. novyi type A isolates were initially cultured by the local microbiology laboratories except two that required the more specialised anaerobic and molecular techniques of the two reference laboratories. As these cultures are difficult to identify by standard hospital laboratory techniques, isolates of C. novyi type A were formally identified by both the PHLS Anaerobe Reference Unit (ARU) and CDC. There was no evidence of $B$. anthracis in any of 12 blood or 13 heroin samples tested at CAMR and CDC. In one patient, indistinguishable strains of Bacillus cereus were isolated from both tissue and a heroin sample in his possession. The only clostridia isolated from heroin cultured at the ARU were one isolate of $C$. perfringens and one of $C$. saccharolyticum. All cultured heroin was negative for $C$. novyi.

\section{Retrospective case-finding}

Among post-mortem examinations for 1995-1999, there were three cases, one each in 1996, 1997 and 1999, with clinical and post-mortem features corresponding with the definite case definition.

The WCC investigation at hospitals A and B revealed a total of 22 patients in the previous year with a WCC $>60 \times 10^{9} / \mathrm{L}$; these included seven known outbreak cases. Of the remainder, none fulfilled the case definition. The more comprehensive investigation, at hospital A, revealed 19 patients $<50$ years old with a WCC $>30$ $\times 10^{9} / \mathrm{L}$. All relevant cases from this outbreak were identified - indicating a high sensitivity of the screen. None of the others met the case definition criteria.

\section{Clinical, pathological and microbiological correlation (Table 4)}

Statistically significant relationships between the following characteristics were demonstrated: WCC $>30$ $\times 10^{9} / \mathrm{L}$ and definite case status; extensive oedema and WCC $>30 \times 10^{9} / \mathrm{L}$; and extensive oedema and definite case status. Associations between the presence of $C$. novyi and definite case status, WCC $>30 \times 10^{9} / \mathrm{L}$ and extensive oedema were present but did not achieve statistical significance.

\section{Communication and advice}

The team held two news conferences, issued 14 news releases and communicated regularly by fax with general practitioners, hospitals and services for drug users. Leaflets and posters were printed and distributed to all agencies that interfaced with drug users in the Greater Glasgow area. IDUs were advised to smoke rather than inject heroin. If injecting heroin could not be avoided, the advice was not to inject into muscle or skin and to use as little acid as possible to dissolve the heroin, as excess acid may damage the muscle or tissue and act as a focus for infection. IDUs were advised to seek medical help urgently if they developed an abscess or painful injection site.

Fifty doctors met in June 2000 to generate management guidelines, which were disseminated to hospitals and general practices throughout GGHB. Surgical debridement is the mainstay of therapy. The recommended antimicrobial regimen included gentamicin, flucloxa- 
Table 3. Clinical features, post-mortem and microbiological findings of cases

\begin{tabular}{|c|c|c|}
\hline Clinical features (all Scotland) & $\begin{array}{c}\text { Definite } \\
\text { cases } \\
(n=23)\end{array}$ & $\begin{array}{c}\text { Probable } \\
\text { cases } \\
(n=37)\end{array}$ \\
\hline Mean interval from injection to presentation (days) & 4.2 & 6.9 \\
\hline Fatal cases & 20 & 3 \\
\hline Found dead at home & 2 & 2 \\
\hline Presented to hospital in extremis & 3 & 0 \\
\hline Died despite being admitted to ITU & 13 & 1 \\
\hline Surviving cases & 3 & 34 \\
\hline Admitted to ITU & 3 & 5 \\
\hline Surgery performed & 11 & 23 \\
\hline Antibiotics received & 20 & 35 \\
\hline \multicolumn{3}{|l|}{ Surgical findings } \\
\hline Necrosis & 9 & 17 \\
\hline Gas & 4 & 2 \\
\hline Pus & 1 & 4 \\
\hline Odour & 0 & 1 \\
\hline Injection site oedema & 22 & 28 \\
\hline $\begin{array}{l}\text { Highest WCC, range }\left(10^{9} / \mathrm{L}\right) \\
\text { (median) }\end{array}$ & $\begin{array}{l}19.4-153 \\
(60.0)\end{array}$ & $\begin{array}{l}5.9-45.6 \\
(12.0)\end{array}$ \\
\hline Post-mortem findings (West of Scotland) & $(n=16)$ & $(\mathbf{n}=3)$ \\
\hline Signs of long-term muscle- or skin-popping & 14 & 2 \\
\hline Superimposed, scabbed ulcers (black) & $7(3)$ & $1(0)$ \\
\hline Generalised lower limb swelling or tissue oedema & 14 & 2 \\
\hline Pleural effusion $(400-1200 \mathrm{ml})$ & 13 & 1 \\
\hline Pericardial effusion & 8 & 0 \\
\hline \multicolumn{3}{|l|}{ Site of severe inflammation } \\
\hline Deltoid & 2 & 0 \\
\hline Buttock or thigh & 14 & 3 \\
\hline Necrotising fasciitis & 15 & 1 \\
\hline \multicolumn{3}{|l|}{ Other signs } \\
\hline Gas within retroperitoneum & 3 & 1 \\
\hline Abscess cavity & 7 & 2 \\
\hline Significant pathogens (West of Scotland) & $(\mathbf{n}=\mathbf{2 0})$ & $(\mathbf{n}=35)$ \\
\hline C. novyi type A & 5 & 2 \\
\hline C. novyi type $\mathrm{A}+C$. perfringens & 2 & 3 \\
\hline Clostridia $+S$. aureus & $1^{*}$ & \\
\hline C. perfringens & 1 & 2 \\
\hline S. aureus & 2 & 4 \\
\hline$S$. aureus $+\mathrm{Gp}$ A $\beta$-haemolytic streptococcus & 1 & 2 \\
\hline S. aureus $+\mathrm{Gp}$ B $\beta$-haemolytic streptococcus & - & 1 \\
\hline S. aureus $+\mathrm{Gp} \mathrm{C} \beta$-haemolytic streptococcus & - & 1 \\
\hline Fusobacterium necrophorum & - & 1 \\
\hline Streptococcus milleri & - & 2 \\
\hline B. cereus & - & 1 \\
\hline No samples taken & 1 & \\
\hline No significant organisms isolated & 7 & 16 \\
\hline
\end{tabular}

*This was the first Scottish case. Although a Clostridium species was grown from ante-mortem tissue, this was neither identified to species nor retained. The clinico-pathological picture fits that of infection with $C$. novyi or $C$. sordellii.

cillin, benzyl penicillin, metronidazole and clindamycin (which, theoretically, may switch off toxin production [10]), thereby covering the most common causes of severe soft tissue infection in IDUs (i.e., Staphylococcus aureus, group A $\beta$-haemolytic streptococci and anaerobes). However, for most of the definite cases, such antibiotic and other therapy proved to be ineffective once multi-system failure had developed.

An outbreak website (www.iduoutbreak.abelgratis.com) comprising epidemiological and clinical details, health promotion advice and treatment guidelines was established.

\section{Discussion}

This outbreak appears to have resulted from exposure to a large batch of contaminated heroin. This is suggested by the similarity of the clinical features and injecting methods of the cases, their temporal and geographical distribution, the high proportion that knew, and injected with, each other and the occurrence of similar contemporaneous outbreaks in Dublin and parts of England. According to police intelligence, the distribution of the clusters in Glasgow reflected specific recognised routes of heroin distribution. To our knowledge, this is the first published report of an outbreak of this type.

C. novyi was not isolated in all cases for several reasons. Firstly, the definite case definition is not specific for $C$. novyi. Rather it defines a clinical syndrome that could be caused by various other toxinproducing organisms which cause severe soft tissue infection, necrotising fasciitis, multiple organ failure 
Table 4. Relationships among extent of injection site oedema, C. novyi isolation, WCC and case status

\begin{tabular}{|c|c|c|c|c|c|}
\hline \multirow[b]{2}{*}{ Parameter } & & \multicolumn{4}{|c|}{ C. novyi status } \\
\hline & & Total & $\begin{array}{c}\text { C. novyi } \\
\text { positive (\%) }\end{array}$ & OR & $95 \%$ CI (Yates) \\
\hline \multirow[t]{2}{*}{ Case Status } & Definite & 23 & $8(35 \%)$ & 3.41 & $0.82-14.81$ \\
\hline & Probable & 37 & $5(14 \%)$ & 1 & \\
\hline \multirow[t]{3}{*}{ WCC } & $>30 \times 10^{9} / \mathrm{L}$ & 23 & $6(26 \%)$ & 1.84 & $0.41-8.48$ \\
\hline & $<30 \times 10^{9} / \mathrm{L}$ & 31 & $5(16 \%)$ & 1 & $\ldots$ \\
\hline & Data missing & 6 & 2 & $\ldots$ & \\
\hline \multirow[t]{5}{*}{ Oedema* } & Extensive & 27 & $9(33 \%)$ & 2.83 & $0.55-16.06$ \\
\hline & Limited & 20 & $3(15 \%)$ & 1 & $\ldots$ \\
\hline & Data missing & 13 & 1 & $\cdots$ & $\cdots$ \\
\hline & \multicolumn{5}{|c|}{ Case status } \\
\hline & & Total & Definite & OR & $95 \% \mathrm{CI}$ \\
\hline \multirow[t]{3}{*}{ WCC } & $>30 \times 10^{9} / \mathrm{L}$ & 23 & $20(87 \%)$ & 200 & $16.4-5901$ \\
\hline & $<30 \times 10^{9} / \mathrm{L}$ & 31 & $1(3 \%)$ & 1 & $\ldots$ \\
\hline & Data missing & 6 & 2 & . & $\ldots$ \\
\hline \multirow[t]{5}{*}{ Oedema* } & Extensive & 27 & $20(74 \%)$ & 54.3 & $5.7-1307$ \\
\hline & Limited & 20 & $1(5 \%)$ & 1 & $\ldots$ \\
\hline & Data missing & 13 & 2 & $\cdots$ & $\cdots$ \\
\hline & \multicolumn{5}{|c|}{ Highest WCC } \\
\hline & & Total & $>30 \times 10^{9} / \mathrm{L}$ & OR & $95 \% \mathrm{CI}$ \\
\hline \multirow[t]{3}{*}{ Oedema* } & Extensive & 23 & $18(78 \%)$ & 30.6 & $4.3-286$ \\
\hline & Limited & 19 & $2(11 \%)$ & 1 & $\ldots$ \\
\hline & Data missing & 18 & 3 & $\ldots$ & $\ldots$ \\
\hline
\end{tabular}

* Categorisation of oedema was as follows. Data missing: no description of oedema (or synonym) made in clinical record where expected if present (so that it appeared a 'significant negative') or, for post-mortem cases, the feature was not found. Limited: oedema present but in extent or degree consistent with a typical injection site abscess (if size recorded, not extending beyond a diameter of $8 \mathrm{~cm}$ ). Extensive: oedema greater in extent or intensity, or both, than a typical abscess (pronounced oedema extending beyond $8 \mathrm{~cm}$ or causing compartment syndrome, for example).

and death in IDUs. Indeed group A $\beta$-haemolytic streptococci, $S$. aureus and $C$. perfringens were isolated from some definite cases. Secondly, in one of the initial fatal cases, no microbiological specimens were taken. Thirdly, in some cases, post mortem had been delayed and the consequent specimens were therefore subject to microbial overgrowth and contamination. Fourthly, in some cases broad-spectrum antimicrobial therapy had been instituted before adequate tissue sampling. Finally, although $C$. novyi was grown from 11 of the 12 (West of Scotland) cases within $48 \mathrm{~h}$ by standard anaerobic techniques, subsequent experience showed that the employment of more sophisticated and prolonged (2 weeks) incubation improved the yield of these fastidious anaerobes.

Where the likely pathogen was identified, this was $C$. novyi in seven (64\%) definite and only five (23\%) probable cases $(\mathrm{p}=0.06$, two-tailed Fisher's exact test). The probable category definition is less specific than that of the definite one and will include coincidental 'background' soft tissue infections among IDUs. It is possible that some of the 37 probable cases did not progress to definite status because timely surgical debridement $(23 ; 62 \%)$ or antibiotic therapy $(35 ; 95 \%)$ prevented multi-system failure.

Consequently, we believe that the detection of $C$. novyi type A in 13 of the 60 cases is of aetiological importance. C. novyi is not a normal commensal of the human gastrointestinal tract [11] but is a recognised cause of clostridial myonecrosis, reported particularly during World Wars I and II [12]; it is also a significant cause of infection in large herbivores [12]. Such previously described cases had many of the clinicopathological features of the current series; these include extensive oedema (the organism's archaic name is $C$. oedematiens) caused by the production of $a$-toxin [13]. However, one notable feature was the occurrence of a leukaemoid reaction in many of the outbreak cases. In man such a reaction is rare outwith malignancy. Infective causes include $B$. anthracis, certain fungi and some other species of clostridia such as $C$. sordellii [14].

The highly significant association between being a definite case and having injected extravascularly is particularly striking because most IDUs in Glasgow inject intravenously (personal communication, A Taylor, SCIEH).

The findings are consistent with the following hypothesis. IDUs injected an acidic solution of street heroin, contaminated with spores of $C$. novyi type A (with or without other organisms or unidentified co-factors) either intramuscularly (muscle-popping) or subcutaneously (skin-popping). 
The acidic solution devitalised the tissue [15], thus favouring the propagation of anaerobic infection. Toxin production led to the development of a severe localised inflammatory reaction with marked oedema which, in some cases, was followed by a life-threatening systemic illness, characterised by hypotension, a leukaemoid reaction and necrotising fasciitis.

At the time of the outbreak, toxicology of seized heroin samples in the areas affected revealed heroin that was about twice as concentrated as usual (or elsewhere at the time), suggesting that it had not been cut; it had a 'purity' of $60-80 \%$ compared with a usual $30-40 \%$ [16]. Thus, extravascular injectors may have been injecting more heroin (and any contaminants) which may have required more acid to dissolve it.

Two critical factors combined to spawn this unique outbreak: the behaviour of muscle- and skin-popping and the suspected contamination of the heroin with $C$. novyi. The word 'popping' refers to the sensation felt by the drug injector when the needle point traverses a fibrous fascial layer; acidic injectate is then deposited deep to a fascial plane - probably the ideal conditions for the generation of necrotising fasciitis. In contrast, spores introduced by intravenous injection of contaminated heroin would be neutralised by the normal host immune response, unless extravasation occurred. Thus intravenous injection would not be expected to cause the local, and then systemic, disease described here. The almost equal numbers of male and female cases differed from the gender distribution of the Scottish IDU population (typically the male:female ratio is $2.5: 1$ ); this probably reflects an increased prevalence of muscle-popping in females.

Thus, the relationships between route of heroin administration and harm are complex: intravenous injection increases some risks (of acute overdose, for example) but decreases others (in this case, that of risk of severe soft tissue infection).

How and when the contamination of heroin occurred is unknown; nevertheless, the extent of the contamination was sufficient to cause many casualties among IDU populations in Britain and Ireland over many weeks. The origins of the street heroin in the UK and Ireland are found in south-west Asia, particularly Afghanistan; given the non-sterile methods of its production and transport, the plausibility of microbial contamination is considerable [17]. Indeed, although C. novyi was not grown from any heroin samples sourced in this investigation, two other clostridia were. Furthermore, among heroin IDUs in California, $C$. botulinum $[18,19]$ and $C$. sordellii [20] have been associated with wound botulism and necrotising fasciitis, respectively. In 2000, a heroin IDU in Norway developed anthrax [21]. During Aug. 2000-Sept. 2001, two cases of wound botulism [22, 23] and one case of necrotising fasciitis due to C. sordellii occurred in Glasgow IDUs.
Therefore, there appears to be a clear association between muscle- and skin-popping and the occurrence of disease mediated by various anaerobic and aerobic toxin-producing spore-forming organisms. The multifactorial aetiology of this outbreak echoes the words of Ogilvie [12] (as quoted by MacLennan) in discussing true invasive myonecrosis: 'it is a disease associated with a particular opportunity rather than a particular organism'. So, crucially, prevention and treatment of these cases must be aimed at removal of that opportunity, i.e., quick and adequate surgical debridement with appropriate antibiotic cover.

The advice to drug users about the need to avoid muscle-popping may have prevented some disease. However, the alternatives for muscle-poppers were limited: smoking heroin is uneconomic for heavily dependent users and the methadone treatment programme was already over-stretched. Thus, it is likely that the outbreak was limited by contaminated heroin either being used up, or withdrawn by dealers keen to protect their business.

The problem of serious disease associated with musclepopping is an emerging one. With ongoing turmoil in south-west Asia, bacterial contamination of heroin remains likely during production or transportation. Accordingly, continued vigilance is warranted. The development of international surveillance systems is required to monitor the incidence of severe soft tissue infection among IDUs and the microbiology and composition of heroin.

Many staff at the following institutions gave generously of their time and skill during the outbreak: Scottish Centre for Infection and Environmental Health, Glasgow; Centers for Disease Control and Prevention, Atlanta, USA; Public Health Laboratory Service, Anaerobe Reference Unit, Central Public Health Laboratory and Communicable Disease Surveillance Centre; Centre for Applied Microbiology \& Research; Greater Glasgow Health Board; haematology and microbiology departments of Glasgow Royal Infirmary, Stobhill Hospital and Victoria Infirmary, Glasgow. In particular, we recognise the contribution of Dr J. Lingappa, CDC, who was based in Glasgow during part of the investigation, and Dr P. Redding, Victoria Infirmary, who identified the index cases.

\section{References}

1. Oppenheimer E, Tobutt C, Taylor C, Andrew T. Death and survival in a cohort of heroin addicts from London clinics: a 22-year follow-up study. Addiction 1994; 89: 1299-1308.

2. Frischer M, Goldberg D, Rahman M, Berney L. Mortality and survival among a cohort of drug injectors in Glasgow, 19821994. Addiction 1997; 92: 419-427.

3. Frischer M, Leyland A, Cormack R et al. Estimating the population prevalence of injection drug use and infection with human immunodeficiency virus among injection drug users in Glasgow, Scotland. Am J Epidemiol 1999; 138: 170-181.

4. Jackson G. Drug-related deaths in Scotland in 2000. Occasional paper no. 5. Edinburgh, General Register Office for Scotland. 2001.

5. Graham CA, McNaughton GW, Crawford R. 'Popping': a cause of soft tissue sepsis in chronic drug abusers. Eur $J$ Emerg Med 1999; 6: 259-261.

6. Strang J, Keaney F, Butterworth G, Noble A, Best D. Different forms of heroin and their relationship to cook-up techniques: data on, and explanation of, use of lemon juice and other 
acids. Subst Use Misuse 2001; 36:573-588.

7. CDC. Unexplained illness and death among injecting drug users - Glasgow, Scotland; Dublin, Ireland; and England, April-June 2000. MMWR Morb Mortal Wkly Rep 2000; 49: 489-492.

8. Holdeman LV, Moore WEC, Cato EP. Anaerobe laboratory manual, 4th edn. Blacksburg, VA, Virginia Polytechnic Institute and State University. 1977.

9. Welch AR, Borriello SP, Barclay FE. Simplified procedure for tissue culture in routine detection of cytotoxins. $J$ Clin Pathol 1985; 38: 835-837.

10. Zimbelman J, Palmer A, Todd J. Improved outcome of clindamycin compared with beta-lactam antibiotic treatment for invasive Streptococcus pyogenes infection. Pediatr Infect Dis J 1999; 18: 1096-1100.

11. Draser BS, Duerden BI. Anaerobes in the normal flora of man. In: Duerden BI, Draser BS (eds) Anaerobes in human disease. London, Edward Arnold. 1991: 162-179.

12. MacLennan JD. Histotoxic clostridial infections of man. Bacteriol Rev 1962; 26: 177-276.

13. Bette P, Frevert J, Mauler F, Suttorp N, Habermann E. Pharmacological and biochemical studies of cytotoxicity of Clostridium novyi type A alpha-toxin. Infect Immun 1993; 57: 2507-2513.

14. McGregor JA, Soper DE, Lovell G, Todd JK. Maternal deaths associated with Clostridium sordellii infection. Am J Obstet Gynecol 1989; 161: 987-995.

15. Napaporn J, Thomas M, Svetic KA, Shahrokh Z, Brazeau GA. Assessment of the myotoxicity of pharmaceutical buffers using an in vitro muscle model: effect of $\mathrm{pH}$, capacity, tonicity, and buffer type. Pharm Dev Technol 2000; 5: 123-130.

16. Bowen EF. Determination by Sheriff Principal of the Sheriffdom of Glasgow and Strathkelvin following fatal accident inquiries held at Glasgow on the twenty ninth day of October two thousand and one and subsequent days. Glasgow. 2001.

17. Tuazon CU, Hill R, Sheagren JN. Microbiologic study of street heroin and injection paraphernalia. J Infect Dis 1974; 129: 327-329.

18. Passaro DJ, Werner SB, McGee J, McKenzie WR, Vugia DJ. Wound botulism associated with black tar heroin among injecting drug users. JAMA 1998; 279: 859-863.

19. Werner SB, Passaro D, McGee J, Schechter R, Vugia DJ. Wound botulism in California: 1951-1998: recent epidemic in heroin injectors. Clin Infect Dis 2000; 31: 1018-1024.

20. Kimura AC, Higa JI, Levin RM, Vugia DJ. Necrotising fasciitis and Clostridium sordellii among black tar heroin users. In: Proceedings of the 39th Annual Meeting of the Infectious Diseases Society of America, San Francisco, October 2001. Abstract 110: p. 58

21. Hoiby EA, Caugant DA. Systemic anthrax in an injecting drug user: Oslo, Norway April 2000. Eurosurveillance Weekly 2000; Issue 19: 11 May.

22. Hood J, Horne G, Sweeney G, Baird K. Third case of wound botulism in an injecting drug user. SCIEH Weekly Report 2000; 34: 200.

23. SCIEH. Wound botulism in an injecting drug user. SCIEH Weekly Report 2001; 35: 248 